\title{
Potential use of medicinal plants from Argentinean highland as agent anti-photoaging
}

\author{
María Eugenia Orqueda $\mathrm{PhD}^{1}$ (D) | María Alejandra Moreno $\mathrm{PhD}^{1}$ (D) | \\ Iris Catiana Zampini PhD ${ }^{1}$ (D) | Karent Bravo $\mathrm{PhD}^{2}$ | Edison Osorio $\mathrm{PhD}^{2}$ | \\ María Inés Isla PhD ${ }^{1}$
}

${ }^{1}$ Instituto de Bioprospección y Fisiología Vegetal (INBIOFIV-CONICET-UNT).

Facultad de Ciencias Naturales e IML. Universidad Nacional de Tucumán., San

Miguel de Tucuman, Argentina

${ }^{2}$ Grupo de Investigación en Sustancias Bioactivas. Facultad de Ciencias

Farmacéuticas y Alimentarias. Universidad de Antioquia., Medellin, Colombia

\section{Correspondence}

Maria Ines Isla, CONICET Tucuman, San

Miguel de Tucuman, Argentina.

Email:misla@tucbbs.com.ar

Funding information

Universidad Nacional de Tucumán, Grant/ Award Number: SCAIT-UNT(G533,G637);

Universidad de Antioquia, Grant/Award Number: UdeA; Consejo Nacional de Investigaciones Científicas y Técnicas, Grant/Award Number: PUE 0011-2018; Fondo para la Investigación Científica y Tecnológica, Grant/Award Number: PICT 3136 and PICT 4436.

\begin{abstract}
Background: The overexposure to sun ultraviolet (UV) radiation produce photoaging by effect of free radicals on lipid, protein, and nucleic acid or by direct activation of responsible enzymes of cleavage of extracellular matrix components (EMC).

Aims: To develop new anti-photoaging agents, the anti-aging activity of four "jarillas" standardized extracts from Argentina (Zuccagnia punctata Cav., Larrea divaricata Cav., Larrea cuneifolia Cav., and Larrea nitida Cav.) were examined.

Methods: The effect on the activity and expression of enzymes related to photoaging (collagenase, hyaluronidase, elastase, tyrosinase) and the antioxidant capacity of four "jarillas" extracts were examined.

Results: The results suggest that "jarillas" extracts could protect EMC by inhibition of skin aging-related enzymes and suppression of the expression of metalloproteinases (MMP-1) in human skin fibroblasts from photoinduced damage. Modulation of MMP-1 expression induced by UV radiation in human skin cells could be associated, at least in part, with the ROS scavenging capacity of "jarilla" extracts. The extract of $Z$ punctata was more active than Larrea species extracts in all the trials. The activity of $Z$ punctata and Larrea extracts could be ascribed to chalcones and lignans, major constituents of "jarillas," respectively.

Conclusions: The results obtained would indicate the potential of these adapted species to live in arid zones of Argentina, exposed to high ultraviolet radiation in production of cosmetic products and justify the promotion of their sustainable use and the development of crops.
\end{abstract}

KEYWORDS

Argentinian "jarillas", collagenase, elastase, hyaluronidase, photoaging

\section{1 | INTRODUCTION}

The skin is one barrier against the detrimental effects of the environment and toxic agents to protect the body. ${ }^{1}$ The overexposure to sun ultraviolet radiation could damage skin and produce photoaging by increases of reactive oxygen species (ROS) that produce alterations on macromolecules and produce enzyme activation that hydrolyze the EMC. ${ }^{2}$ The EMC of epidermis and dermis, including type I collagen, elastin, proteoglycans, and fibronectin, are degraded by the action of enzymes such as matrix metalloproteinases (MMP) which are activated by the genetic induction caused by short UVB wavelengths. ${ }^{2}$ 
Nowadays, cosmetic or cosmeceutical products derived from plants are used as ingredients because they suppress or slow the aging processes of the skin and to contrast the extrinsic ones by ROS scavenging and modulating the activity of enzymes involved in the aging. $^{2}$

In Argentina, in the biogeographic region of Monte, an arid ecosystem, with low temperature, low absolute humidity, and high solar radiation, grows the native plant species of the natural community of "jarillal" formed mainly by Larrea species and Zuccagnia punctata Cav. (Fabaceae). Z punctata, commonly named as "pus pus," "jarilla pispito," "jarilla macho," and "jarilla poposa" is a xerophytic and evergreen shrub. Larrea divaricata Cav. (Zygophyllaceae) (popular names: "jarilla," "jarilla hembra," "chamanilla," "jarilla del cerro," "yarilla"), Larrea nitida Cav. (popular names: "jarilla," "jarilla de la montaña," "crespa," "pispa o pispita," "jarilla fina"), and Larrea cunefolia Cav. (popular name: "jarilla," "jarilla macho," "jarilla crespa," "jarilla norte-sur," "jarilla del campo") are the main species in the "jarillal." L divaricata exert antibacterial, antioxidant, anticandida, and immunomodulatory effect. ${ }^{3-5}$ It was also found that it slows induced apoptosis and cell division. ${ }^{6} \mathrm{~L}$ cuneifolia extracts showed antioxidant, antifungal, and antibacterial activity. ${ }^{4,5}$ Antifungal and antioxidant capacities were demonstrated in L. nitida.$^{5,7}$ Lignans and flavonoids were identified in the three Larrea species. ${ }^{5}$ In $L$ divaricata, $L$ cuneifolia, and $L$ nitida, various lignans were identified, among them, nordihydroguaiaretic acid (NDGA). ${ }^{5}$ This compound was assigned as chemical marker to obtain standardized extracts. ${ }^{5}$

$Z$ punctata is an Argentine medicinal plant widely recognized by its functional properties (antibacterial, antifungal, anti-inflammatory, antigenotoxic, and antioxidant, between other activities). ${ }^{8-12}$ Also, it was reported its activity as inhibitor of chemotherapeutic resistance factors such as efflux pump ${ }^{8}$ and as agent that prevents cardiovascular diseases related to hypercholesterolemia and endothelial dysfunction. ${ }^{13}$ The major bioactive components identified in $Z$ punctata are 2',4'-dihydroxychalcone (DHC), 2',4'-dihydroxy-3'-methoxychalcone $^{8-12}$ that could be assigned as chemical markers. ${ }^{12}$

As the "jarillas" are plant species adapted to live in extreme conditions and have multiple properties that can be used industrially, in Argentina their cultivation in situ is being promoted. Currently, a product against the hair loss of one of the "jarilla" species is already commercialized in Argentina. Microcapsules containing "jarilla" extracts were realized and proved to be suitable for the treatment of vulvovaginal candidiasis. ${ }^{9}$ Despite the knowledge of the chemistry of "jarilla" species and of the wide range of biological properties demonstrated, the anti-aging effects of the "jarillas" species are unknown.

The aim of this research work was to determine the anti-aging activity of standardized extracts of aerial parts of four "jarillas" species. The four hydroalcoholic extracts were previously chemically standardized. 5,9,12 Taking into account the EMA guidelines (2010), the hydroalcoholic extracts of aerial parts from four "jarillas" species could be used in herbal medicinal product as standardized extracts by the content of selected chemical markers. ${ }^{14}$

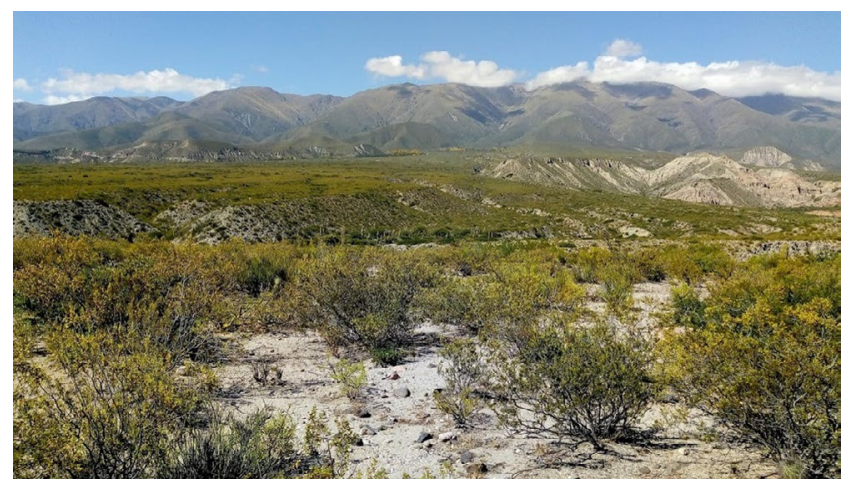

FIGURE 1 Imagen of "jarillal" in Amaicha del Valle, Tucumán, Argentina. Photographs: by authors, in Amaicha del Valle, Tucumán, Argentina

\section{2 | METHODOLOGY}

\section{1 | Plant material}

The plant parts used were leaves and stems, according to the traditional use. Z punctata plants were collected in April 2017 at $2000 \mathrm{~m}$ above sea level (m.a.s.l.) in Amaicha del Valle, Tucumán,

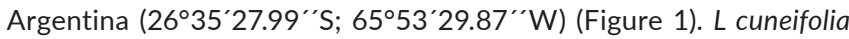

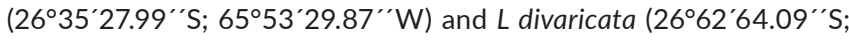
$\left.65^{\circ} 86^{\prime} 81.74^{\prime \prime} \mathrm{W}\right)$ were collected in April 2017 at Amaicha del Valle, Tucumán, Argentina at 2000 m.a.s.l.. The sample of $L$ nitida was collected in Vinchina, La Rioja, Argentina at 3485 m.a.s.l. $\left(28^{\circ} 34^{\prime} 03.74^{\prime \prime} \mathrm{S}\right.$; $\left.68^{\circ} 41^{\prime} 33.74^{\prime \prime} \mathrm{W}\right)$. All the plants were identified by Dra. Soledad Cuello (INBIOFIV-CONICET-UNT). Voucher specimens (L cuneifolia: LIL 614 829; L divaricata: LIL 614 299; L nitida: LIL 615 845; Z punctata: LIL 605 935) are deposited at the Herbarium of Fundación Miguel Lillo (Tucumán, Argentina). The samples were dried in a forced air oven at $40^{\circ} \mathrm{C}$.

\subsection{Preparation and chemical characterization of ethanolic extracts of "jarillas"}

Ground air-dried "jarillas" aerial parts (10 g) were macerated in $60^{\circ}$ ethanol $(200 \mathrm{~mL})$ for $1 \mathrm{~h}$ with ultrasound application in cycles of 10 minutes. The extracts were filtered, taken to dryness under reduced pressure at $37^{\circ} \mathrm{C}$ and lyophilized to afford the dry extracts. ${ }^{5,9}$ Then, the extracts were placed in oxygen barrier bags and vacuum-packed until used (Multivac, D-8941, Germany) and named as ZP: Z punctata, LD: L divaricata, LC: $L$ cuneifolia, and LN: L nitida.

These extracts were analyzed by HPLC (Waters Corporation, Milford, MA, USA) coupled to a diode array detector (Waters 2998 photodiode array detector) according to described conditions in previous reports. ${ }^{5,9,12}$ A solution of $2 \mathrm{mg} / \mathrm{mL}$ of each extract was used. Data collection was carried out with EmpowerTM 2 software. The identification of compounds present in the extracts 
was carried out by comparing retention times and spectral data (220-600 nm) of each peak with those of standards from SigmaAldrich (MO, USA) and Indofine Chemical Company, Inc. The main components or chemical markers 2',4'-dihydroxychalcone (DHC) and nordihydroguaiaretic acid (NDGA) were quantified by using plots relating areas and concentrations of commercial standards.

\section{3 | Enzymatic assays with "jarillas" extracts}

All the enzymatic assays were performed using until $250 \mu \mathrm{g}$ dry weight (DW) of extract $/ \mathrm{mL}$ and following the methodology described previously. ${ }^{15}$ The percent inhibition of the enzymatic activity was calculated using Equation (1). The $I \mathrm{IC}_{50}$ values were determined and defined as the concentration of extract necessary to inhibit the $50 \%$ of enzymatic activity. All of them were expressed as $\mu \mathrm{g} D W$ of extract $/ \mathrm{mL}$.

\subsection{1 | Anti-collagenase activity}

The inhibitory capacity of "jarilla" extracts on collagenase was assayed by EnzCheck ${ }^{\circledR}$ Gelatinase-Collagenase kit (Thermo Fisher Scientific US). Different concentration of extracts or buffer as negative control was added. The fluorescence intensity was measured. Oleanolic acid $(250 \mu \mathrm{M})$ was used as a reference inhibitor. The inhibition percent of collagenase enzyme by the extracts was calculated with the following equation:

$$
\text { Inhibition }(\%)=(\text { M control }-M \text { sample }) / M \text { control } \times 100
$$

Where $M$ control and $M$ sample are the slopes of the fluorescence graph vs time of incubation.

\subsection{2 | Anti-elastase activity}

Elastase inhibition was determined by measured using the EnzCheck ${ }^{\circledR}$ Elastase assay kit (Thermo Fisher Scientific US). Briefly, aliquots of $50 \mu \mathrm{L}$ of different dilutions of "jarilla" extracts or buffer (negative control) were added to each well of a 96-well plate. Then, $50 \mu \mathrm{L}$ of elastine substrate-fluorescein conjugate and $100 \mu \mathrm{L}$ of elastase were added. The fluorescence was determined. Oleanolic acid was used as positive control.

\subsection{3 | Anti-hyaluronidase activity}

The effect of "jarillas" extracts on hyaluronidase enzyme was carried out according to Chompoo et al ${ }^{15}$ with preincubation extracts-enzyme during 10 minutes at $37^{\circ} \mathrm{C}$. The positive control was epigallocatechin gallate (EGCG).

\subsection{4 | Anti-tyrosinase activity}

The assays of tyrosinase inhibition were carried out according to Bravo et al. ${ }^{16}$ Different "jarillas" extract concentrations with and without tannins, buffer (negative control), kojic acid (positive control) were used. The percent inhibition of tyrosinase was calculated using Equation (1).

A size exclusion chromatography using Sephadex LH-20 was performed, in order to eliminate the tannins of the Zuccagnia punctata extract samples. Acetone: water (1:1; v/v) was used as mobile phase. Ethanol $80 \%$ was used with the purpose of recovery polyphenolic compounds. Then, the tannins free $Z$ punctata extract was drying and named as ZP-WT. These extracts were assayed as tyrosinase inhibitors.

\section{4 | Antioxidant capacity of dry extracts}

\subsection{1 | Oxygen radical absorbance capacity assay}

Different dilutions of "jarilla" extracts or Trolox standard was mixed with $150 \mu \mathrm{L}$ of fluorescein $(1 \mu \mathrm{M})$ and incubated at $37^{\circ} \mathrm{C}$ during 30 minutes before the addition of $25 \mu \mathrm{L}$ of $\mathrm{AAPH}$ solution (200 mM), peroxyl radical generator. The fluorescence was measured every 2 minutes for 120 minutes using a Synergy HT MultiMode Microplate Reader.

\subsection{Assays in cell systems}

\subsection{1 | Cell culture}

Dermal human fibroblasts (HDFs) isolated from adult human skin, as well as all the reagents for the culture and maintenance of the cells, were purchased in Life Technologies Inc, USA. HDFs were cultured in DMEM-F12 medium with $10 \%$ fetal bovine serum (FBS) and $100 \mathrm{U} / \mathrm{mL}$ penicillin $-100 \mu \mathrm{g} / \mathrm{mL}$ streptomycin at $37^{\circ} \mathrm{C}$ in a humidified atmosphere with $5 \% \mathrm{CO}_{2}$, with change of medium every $48 \mathrm{~h}$, up to $90 \%$ confluence.

Subsequently, the HDFs were transferred to 96-well plates $(1 \mathrm{x}$ $10^{4}$ cells per well) for the respective analyzes.

\subsection{2 | Cytotoxicity on human dermal fibroblasts by WST-8 assay}

The cytotoxic effect of the extracts on HDFs was evaluated through of the reduction of 2-(2-methoxy-4-nitrophenyl)-3-(4-nitrophenyl)5-(2,4-disulfophenyl)-2H-tetrazolium (WST-8, Dojindo Molecular Technologies Inc, USA) by cellular dehydrogenases. HDFs were treated with different concentrations of extracts in a range between 2.5 and $50 \mu \mathrm{g} D W / \mathrm{mL}$, for 24 hours. After treatment, HDFs were washed with phosphate-buffered saline (PBS) and were incubated in 
presence of reagent WST- 8 at $37^{\circ} \mathrm{C}$ for 2 hours. The absorbance was measured at $450 \mathrm{~nm}$ by a multimodal Synergy microplate reader HT (BioTek Instruments, Inc, Winooski, USA).

\subsection{3 | Production and quantification of metalloproteinase 1 (MMP-1) in human dermal fibroblasts}

MMP-1 produced by HDF culture in presence or absence of "jarillas" extracts was determined by the ELISA technique (Human Total MMP-1 DuoSet Kit).

After this treatment, the cells were washed with PBS, then 100 $\mu \mathrm{L}$ of fresh medium without FBS was added, and the HDFs were subjected to a dose of UVB radiation of $100 \mathrm{~mJ} / \mathrm{cm}^{2}$ using a system of UV radiation Bio-Sun, from the Vilber Lourmat Company (France). Afterward, the dishes containing the cells were incubated at $37^{\circ} \mathrm{C}$ in a humidified atmosphere with $5 \% \mathrm{CO}_{2}$ for 72 hours. The concentration of MMP-1 was determined following the instructions of maker. For reference, a solution of EGCG at $25 \mu \mathrm{M}$ was used.

To determine the MMP-1 concentration after treatment with the sample, a response-dose model (log concentration vs. absorbance) was performed using a calibration curve with known concentrations of a recombinant human MMP-1 standard, in a range of 156 to $20000 \mathrm{ng} / \mathrm{mL}$.

\subsection{4 | Effect of "jarillas" extracts on reactive oxygen species production in human dermal fibroblasts}

HDFs $\left(5 \times 10^{4}\right)$ were placed in 96-well black plates and treated for 2 hours at $37^{\circ} \mathrm{C}$ with different solutions of extract at a final concentration of $6.25,12.5$, and $25 \mu \mathrm{g} D \mathrm{DW} / \mathrm{mL}$. Subsequently, $10 \mu \mathrm{L}$ of $2^{\prime}, 7^{\prime}$-dichlorofluorescin diacetate (DCFH-DA) was added and incubated again at $37^{\circ} \mathrm{C}$ during 45 minutes. HDFs were subjected to a dose of UVB radiation of $200 \mathrm{~mJ} / \mathrm{cm}^{2}$ using UV radiation system BioSun and incubated again for 30 minutes at $37^{\circ} \mathrm{C}$. Finally, the fluorescence (DCF) was measured (485 nm excitation and $520 \mathrm{~nm}$ emission wave) in a multimodal microplate reader Synergy HT. The levels of intracellular ROS are described as the increase in fluorescence with respect to nonirradiated cells.

\section{3 | RESULTS AND DISCUSSION}

Nowadays, the search for natural products that can reduce photoaging is booming in the field of dermatology. ZP, LC, LD, and LN, four "jarillas" species from region Monte in Argentina (Figure 2), are active as antibacterial, antifungal, antioxidant, and anti-inflammatory. ${ }^{4,5,8-12}$ The hydroethanolic extracts obtained from them were previously chemically characterized and standardized. ${ }^{5,9,12}$ In this work, the potential use of these extracts in phytocosmetic or phytotherapy was analyzed.

\section{1 | Identification and quantification of phenolic compounds by HPLC-DAD}

The chemical composition of each plant extract was previously determined by HPLC-MS/MS, and chemical markers were identified, DHC in $Z$ punctata extract and NDGA in $L$ cuneifolia, $L$ nitida, and $L$ divaricata extracts. ${ }^{5,9,12}$ In this work, the extracts were analyzed by HPLC-DAD to be compared with the previously standardized extracts. ${ }^{5,9,12}$ In the extracts were identified and quantified the chemical markers, DHC (40 $\mu \mathrm{g} / \mathrm{mg}$ DW) in Z punctata and NDGA in Larrea extracts $(140 \mu \mathrm{g} / \mathrm{mg}$ DW in L divaricata; $268 \mu \mathrm{g} / \mathrm{mg}$ DW in L nitida; $158 \mu \mathrm{g} / \mathrm{DW}$ in L cuneifolia). The quantities of each of them were similar to previous determinations in standardized extracts. ${ }^{12}$

\section{2 | Anti-aging activity of "jarillas" ethanolic extracts in cell-free systems}

\subsection{1 | Effect on enzyme activity}

In this frame, was evaluated the potential of Argentine native plant extracts to inhibit enzymatic activity of collagenase, elastase, hyaluronidase, and tyrosinase. The collagenase inhibition could represent a potential strategy for the prevention or treatment of photoaging induced by UV radiation. ${ }^{1,2}$ The inhibition percentages of 100 and $250 \mu \mathrm{g} / \mathrm{mL}$ of ZP, LD, LC, and LN extracts are shown in Figure 3 and the $\mathrm{IC}_{50}$ values of the collagenase activity in Table 1. ZP was the most active against the collagenase enzyme with $I_{50}$ values of $2.50 \mu \mathrm{g} / \mathrm{mL}$ of extract. The $\mathrm{IC}_{50}$ values of ZP without tannins were higher than ZP total extract on collagenase. These results are indicative that tannins would be one of the components responsible for the anti-collagenase activity of $Z$ punctata. ${ }^{17}$ Chalcones, major components of ZP extracts, ${ }^{8}$ may also be responsible for the anticollagenase effect since these generally have recognized anti-aging, antioxidant, and anti-inflammatory properties. ${ }^{18}$ Due to reports on the effect of flavonoids with hydroxyl groups in rings $A$ and $B$ on collagenase activity, the activity of $Z$ punctata extracts could be attributed to the interaction of hydroxyl groups present in tannins and chalcones with functional groups of amino acids present in the active site or the collagenase side chain. ${ }^{19}$ Furthermore, the hydrophobic interaction that occurs between the benzene ring of these compounds and the collagenase enzyme could cause conformational changes that decrease enzyme activity. ${ }^{20}$

All Larrea species were active as inhibitors of collagenase but $L$ nitida was more active than $L$ divaricata and $L$ cuneifolia. The presence of lignans and especially nordihydroguaiaretic acid (NDGA) in the extracts of the three Larrea species used in this work were previously demonstrated. ${ }^{5}$ In fact, these compounds are major components of $L$ cuneifolia extracts and could be responsible of collagenase 
inhibitory effect. Recently was demonstrated by other authors that the NDGA can improve the stability of some types of collagen by improving resistance to hydrolysis caused by type I collagenase ${ }^{21}$ and inhibiting the activity of MMP-1 in human fibroblast cultures. ${ }^{22}$

The elastin is a protein responsible of elasticity of the skin and lung and is hydrolyzed by elastase with a consequent loss of skin resistance and the appearance of wrinkles. Elastase activity has been reported to increase with age. The search elastase inhibitor could also be an important target to maintain the integrity of elastin during photoaging. ${ }^{10}$ The $\mathrm{IC}_{50}$ values of "jarillas" on elastase activity were not calculated due to that the inhibition percentages were low even at the maximal assayed concentration $(250 \mu \mathrm{g} / \mathrm{mL})$. Nevertheless, it is important to highlight that the elastase inhibition percentage by $Z$ punctata was comparable with reported by Sacan et al ${ }^{23}$ for the Aloe vera at same concentration of extract $(100 \mu \mathrm{g} / \mathrm{mL})$. The anti-elastase activity of $Z$ punctata extract could be attributed to chalcone content. ${ }^{24}$ However, the potency of extracts enriched in phenolic compounds was lower than oleanolic acid, a natural inhibitor of elastase with structural characteristics (carboxyl function at position 28 , and a double bond) necessary to produce elastase inhibition. $^{25}$

The skin requires certain components suitable to support dermal proliferation, migration, and regeneration. Hyaluronic acid $(\mathrm{HA})$ is a natural molecule formed by glucose and considered important for skin rejuvenation, maintenance of moisture and viscosity and reduction of the permeability of extracellular fluid. ${ }^{26}$ Hyaluronidase (Hyal) is a hydrolytic enzyme that acts degrading the HA present in the $\mathrm{EMC}$ of numerous tissues in response to various stimuli. Protect $\mathrm{HA}$ from the action of Hyal is a fundamental objective to maintain the structure of the connective tissues of the skin. All "jarilla" extracts were hyaluronidase inhibitors, with $\mathrm{IC}_{50}$ values between 10.00 and $175.23 \mu \mathrm{g} / \mathrm{mL}$ (Table 1). The anti-hyaluronidase activity of Zuccagnia extracts was much higher than Camelia sinensis $(74.85 \mu \mathrm{g} / \mathrm{mL}){ }^{27}$ In inflammatory diseases of the lungs and skin, it has been found that Hyal is overexpressed. Low molecular mass fragments of hyaluronan

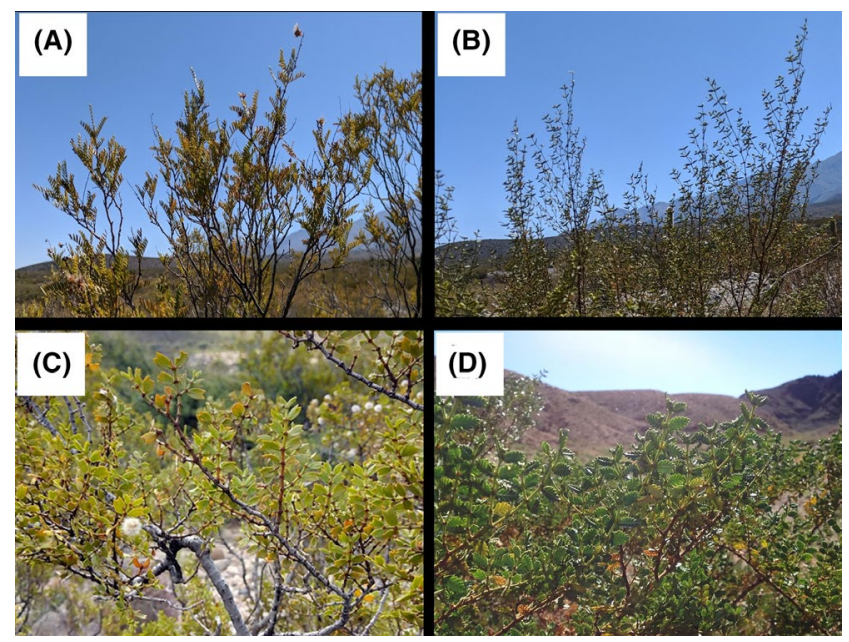

FIGURE 2 "Jarillas" species: A, Zuccagnia punctata, B, Larrea divaricata, C, Larrea cuneifolia, and D, Larrea nitida. Photographs: by authors, in Amaicha del Valle, Tucumán, Argentina have also been shown to trigger inflammation by stimulating gene expression and the synthesis of pro-inflammatory mediators. ${ }^{28}$ For this reason, extracts with enzyme inhibitory activity could also exhibit anti-inflammatory activity. In previous works was reported that $Z$ punctata extracts could be inhibitors of pro-inflammatory enzymes such as cyclooxygenase-2, lipoxygenase, and phospholipase A2 and the authors attributed this inhibitory effect to chalcones, components of $Z$ punctata extract. ${ }^{8}$ However, in this paper has been shown that the anti-hyaluronidase activity of $Z$ punctata extracts without tannins was lower than $Z$ punctata extract with tannins (Table 1). This result indicates that the inhibitory activity of $Z$ punctata extract could be attributed to both chalcones and tannins. As regards the behavior of Larrea extracts on hyaluronidase, its inhibitory activity could be attributed principally to NDGA with demonstrated anti-inflammatory activity on lipoxygenase activity. ${ }^{29}$

Tyrosinase is an enzyme involved in the melanin biosynthesis, responsible of skin hyperpigmentation. Therefore, it is important to search tyrosinase inhibitors as anti-hyperpigmentation agents. All "jarilla" extracts showed good activity as tyrosinase inhibitors (Figure 3), $97.08 \%$ of inhibition at $100 \mu \mathrm{g} / \mathrm{mL}$ with $I_{50}$ values of 11.50 and $22.30 \mu \mathrm{g} / \mathrm{mL}$ for $Z$ punctata and ZP-WT extracts, respectively (Table 1). No previous studies are reported on in vitro assays against skin enzymes in ZP extracts. However, the anti-tyrosinase activity of $Z$ punctata could be attributed to chalcones and tannins present in the ZP extract. Khatib et al ${ }^{30}$ reported that chalcones formed by a resorcinol moiety on one aromatic ring (hydroxyl groups in 2 '- and 4 '-positions) contribute to increase the inhibition power of chalcones through a mechanism of binding to the active site of the tyrosinase as would be the case of the DHC present in Z punctata extracts. Furthermore, it is documented through molecular docking methods that 4 '-substituted chalcones at ring $\mathrm{A}$ exhibit greater anti-tyrosinase activity than those that are not substituted in this position, as well as, chalcones have greater inhibitory activity than other flavonoids such as flavonols. ${ }^{31,32}$ Larrea extracts were also active against tyrosinase with $\mathrm{IC}_{50}$ values between 39.33 and $76.55 \mu \mathrm{g} / \mathrm{mL}$.

\subsection{2 | Antioxidant capacity}

The increase in ROS production by sunlight UV radiation with the consequent macromolecules damage and skin photoaging has been reported. ${ }^{2}$ Therefore, it is important to analyze whether the "jarilla" extracts, in addition to acting as enzyme inhibitors that lead to the degradation of EMC, are antioxidants or free radical scavengers. In previous papers has been reported the antioxidant activity of "jarillas" extracts. ${ }^{5,8-10}$ The LD extract was more active as ABTS ${ }^{\bullet+}$ scavenger than LC and LN with $\mathrm{SC}_{50}$ values (concentration of extract necessary for scavenged the $50 \%$ of ABTS radicals) of 2.68; 4.10 ; and $4.50 \mu \mathrm{g} \mathrm{GAE} / \mathrm{mL}$, respectively. ${ }^{5}$

Antioxidant capacity on $\mathrm{ABTS}^{\bullet+}$ to $\mathrm{Z}$ punctata extract was previously reported $\left(\mathrm{SC}_{50}\right.$ values of $\left.3.8 \mu \mathrm{g} \mathrm{GAE} / \mathrm{mL}\right){ }^{9}$ In this report, the three maximum values in the ORAC assay were found in the three 
(A)

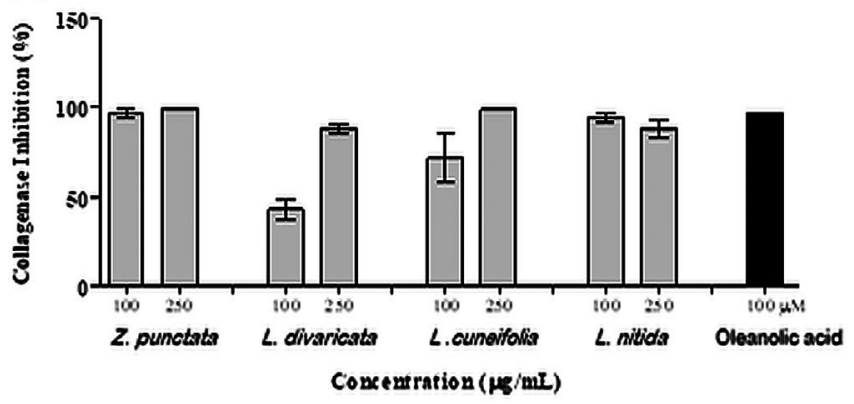

(C)

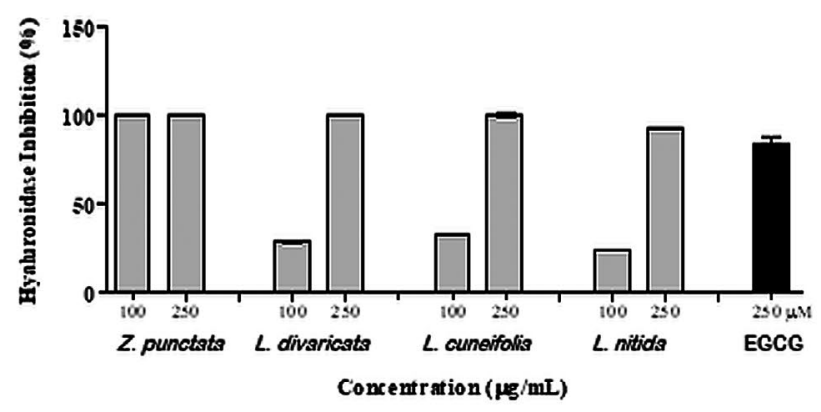

(B)

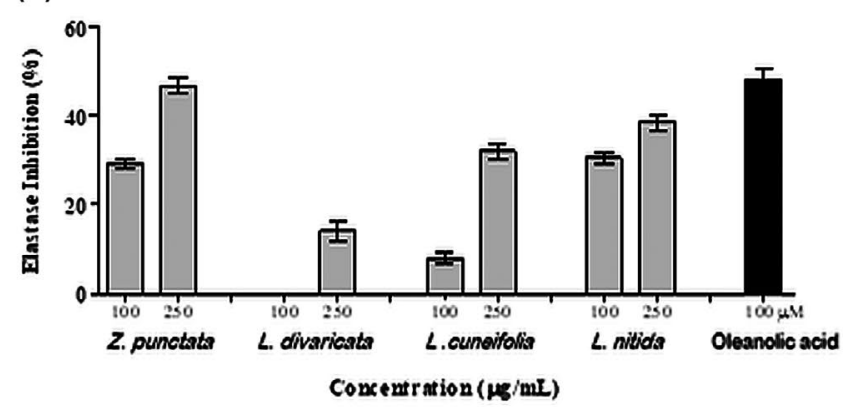

(D)

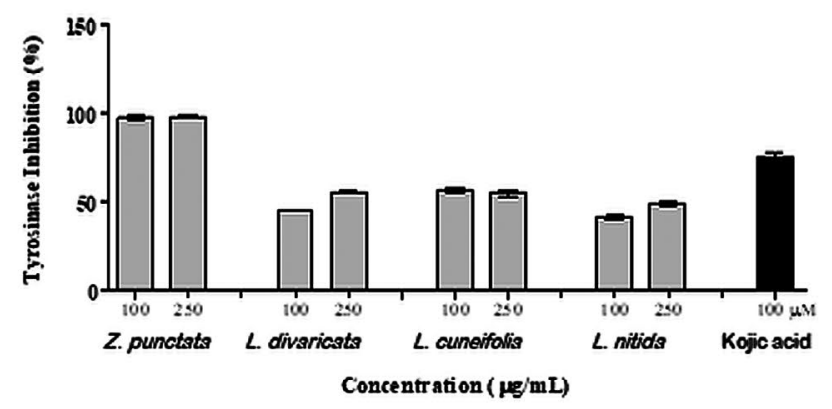

FIGURE 3 Enzymatic inhibition percentages of ethanolic extracts of native plants from northwestern Argentina. A, Collagenase, B, Elastase, C, Hyaluronidase, and D, Tyrosinase. Oleanolic acid was used reference inhibitor in collagenase and elastase assays. Epigallocatechin gallate (EGCG) was used as reference in hyaluronidase assay and kojic acid was used in tyrosinase assay

\begin{tabular}{lccl} 
& \multicolumn{3}{l}{$\mathrm{IC}_{50}(\mu \mathrm{g} / \mathrm{mL})$} \\
\cline { 2 - 4 } Sample & Collagenase & Hyaluronidase & Tyrosinase \\
\hline Zuccagnia punctata & $2.50 \pm 0.09^{\mathrm{a}}$ & $10.00 \pm 0.52^{\mathrm{a}}$ & $11.57 \pm 0.95^{\mathrm{a}}$ \\
\hline Z punctata WT & $22.00 \pm 2.56^{\mathrm{b}}$ & $15.03 \pm 0.20^{\mathrm{b}}$ & $23.54 \pm 1.20^{\mathrm{b}}$ \\
\hline Larrea divaricata & $64.21 \pm 0.90^{\mathrm{d}}$ & $104.25 \pm 1.02^{\mathrm{d}}$ & $76.55 \pm 5.20^{\mathrm{d}}$ \\
\hline Larrea cuneifolia & $39.45 \pm 1.45^{\mathrm{c}}$ & $122.00 \pm 1.03^{\mathrm{e}}$ & $43.61 \pm 3.45^{\mathrm{c}}$ \\
\hline Larrea nitida & $31.90 \pm 1.39^{\mathrm{c}}$ & $175.23 \pm 0.63^{\mathrm{f}}$ & $39.33 \pm 2.36^{\mathrm{c}}$ \\
\hline Control & $81.90 \pm 6.65^{\mathrm{e}}$ & $30.23 \pm 0.86^{\mathrm{c}}$ & $23.22 \pm 0.96^{\mathrm{b}}$ \\
\hline
\end{tabular}

TABLE 1 Effect of ethanolic extracts of "jarillas" on skin aging-related enzymes

Note: All data are shown as the mean \pm SD of three independent experiments. Different letters in the same column show significant differences in $\mathrm{IC}_{50}$ values between each extract according to Tukey's test $(P \leq .05)$. $Z$ punctata WT: Z punctata extract-tannins free.

${ }^{*}$ Control: Oleanolic acid for Collagenase and Hyaluronidase and kojic acid for Tyrosinase.

Larrea species, with higher values than $3300 \mu \mathrm{mol} T \mathrm{TE} / \mathrm{g}$ indicating the antioxidant efficacy of these extracts (Figure 4). Z punctata showed lowest ORAC values.

\section{3 | Anti-aging activity of "jarillas" ethanolic extracts in cell systems}

\subsection{1 | Effect on UV-B-induced MMP-1 production in HDFs}

UV radiation induces the activity of MMP which causes damaging changes in the connective tissue of the skin. ${ }^{2}$ Thus, bioactive "jarillas" extracts at concentrations of 6.25 and $12.5 \mu \mathrm{g} / \mathrm{mL}$ were selected to measure the effect of MMP-1 production in UVBirradiated HDFs. The UVB radiation increased about 4 times the MMP-1 production $(P<.0001)$, Figure 5 . The pretreatment of HDF cultures with "jarillas" extracts reduced the MMP-1 expression after irradiation in a dose-dependent manner. Among extracts, $L$ divaricata extract showed the greatest effect. At $12.5 \mu \mathrm{g} / \mathrm{mL}$, this extract reduced the MMP-1 production by $82 \%$. While the reference compound, EGCG, reduced it by $90 \%$ at $11.5 \mu \mathrm{g} / \mathrm{mL}$ $(25 \mu \mathrm{M})$, other extracts reduced by $60 \%$ the MMP-1 production at $12.5 \mu \mathrm{g} / \mathrm{mL}$. Based on these findings, the ZP extracts can inhibit UV-induced MMP-1 expression in fibroblasts, and this inhibitory effect could be due to the presence of chalcones. ${ }^{5}$ The activity of Larrea extracts could be ascribed to NDGA and lignans reported by Moreno et al. ${ }^{9}$ 


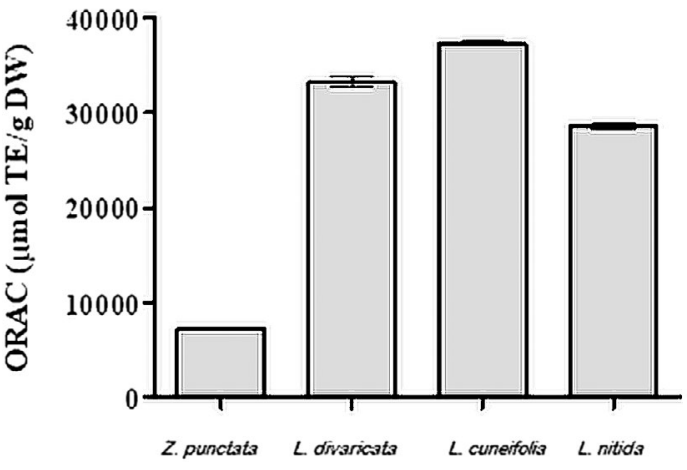

FIGURE 4 Antioxidant capacity of plant extracts expressed as $\mu \mathrm{g}$ of Trolox equivalent per gram of dry extracts

\subsection{2 | Effect on UVB-induced ROS production by HDFs}

The UV radiation drastically increased ROS production in human fibroblasts (more than 18-fold), Figure 6. All "jarillas" extracts significantly reduced more than $50 \%$ of the UVB-induced ROS generation at concentrations between 6.25 and $25 \mu \mathrm{g} / \mathrm{mL}$. At the highest concentration, the reduction was around $72 \%$, except to LD which reduced $66 \%$ of ROS production at $25 \mu \mathrm{g} / \mathrm{mL}$. The effects were similar to control quercetin which reduced 62 and $72 \%$ the ROS generation at 7.5 and $15 \mu \mathrm{g} / \mathrm{mL}$, respectively (25 and $50 \mu \mathrm{M})$. The obtained results suggest the antioxidant capacity of "jarilla" extracts. Modulation of matrix metalloproteinase 1 expression induced by UV radiation in human skin cells could be associated, at least in part, with the ROS scavenging capacity of "jarilla" extracts.

\section{4 | CONCLUSIONS}

The results suggest the ability of some "jarilla" plant extracts to protect the main EMC through a route of inhibition of enzymes related to skin aging and its antioxidant capacity. In addition, the extracts cause the suppression of UV-induced MMP-1 expression in human skin fibroblasts. This result indicates the potential of these extracts

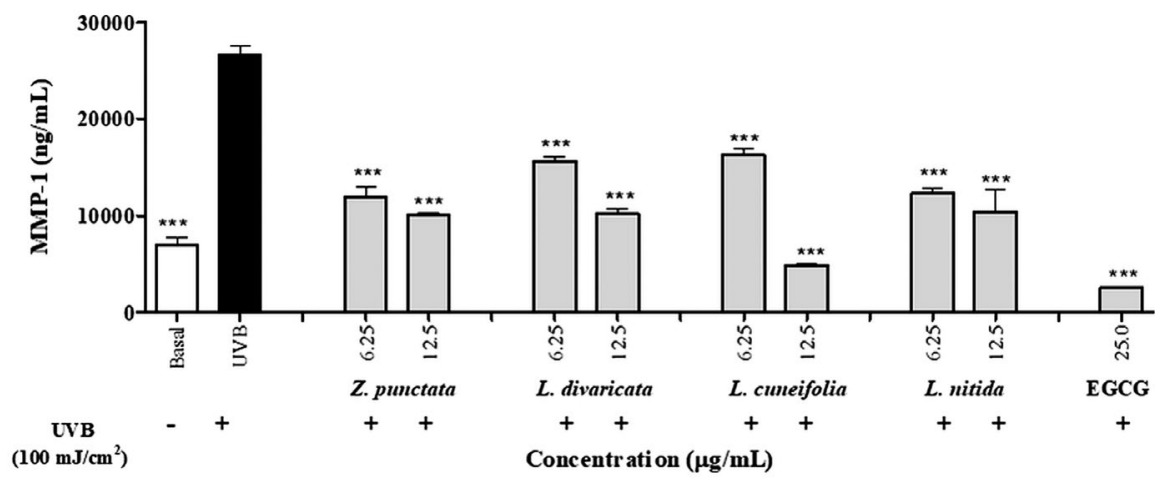

FIGURE 5 Effect of plant extracts on MMP-1 in HDFa after UVB radiation. 1 x $10^{4}$ cells were treated with samples for $24 \mathrm{~h}$ and were then exposed to UVB $\left(100 \mathrm{~mJ} / \mathrm{cm}^{2}\right)$ radiation. The MMP-1 production was determined by ELISA $72 \mathrm{~h}$ after irradiation. Epigallocatechin gallate (EGCG) $25 \mu \mathrm{M}$ was used by reference. All data are shown as the mean $\pm \mathrm{SD}$ of three independent experiments. ${ }^{* * *} \mathrm{P}<.0001$, compared with the UVB-irradiated control

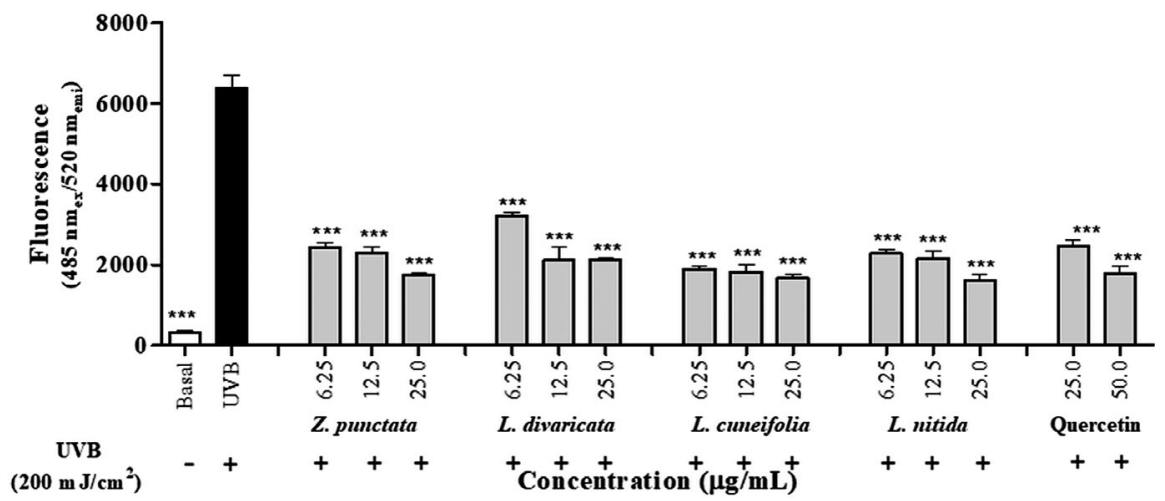

FIGURE 6 Effect of plant extracts on intracellular ROS production in HDFa after UVB radiation. $5 \times 10^{4}$ cells were co-treated with different concentrations of plant extracts for 2 hours. Then, treated and untreated cells were exposed to UVB $\left(200 \mathrm{~mJ} / \mathrm{cm}^{2}\right) \mathrm{radiation}$. The ROS generation was measured by $2^{\prime}, 7^{\prime}$-dichlorofluorescin diacetate assay. Quercetin 25 and $50 \mu \mathrm{M}$ was used by reference. All data are shown as the mean \pm SD of three independent experiments. ${ }^{* * *} P<.0001$, compared with the UVB-irradiated control 
to prevent photoaging. $Z$ punctata standardized extract is the most active in all tests and, therefore, is relevant for use in healthy cosmetic products. The benefic properties of the Argentinian plant extracts against the aging process could be attributed to a set of compounds previously described in them. However, this supports the need to examine extracts from these plant materials more extensively in in vivo models. The loss of biodiversity on the planet is the main incentive to deepen the study of our native species adapted to live in extreme conditions, high ultraviolet radiation and arid zones to promote the crop and sustainable use of them.

\section{CONFLICT OF INTEREST}

The authors declare that there are no conflicts of interest.

\section{DATA AVAILABILITY STATEMENT}

The data that support the findings of this study are available from the corresponding author upon reasonable request.

\section{ORCID}

María Eugenia Orqueda (D) https://orcid. org/0000-0002-9499-1540

María Alejandra Moreno iD https://orcid.

org/0000-0002-0749-8687

Iris Catiana Zampini iD https://orcid.org/0000-0001-7941-1678

María Inés Isla iD https://orcid.org/0000-0002-4261-4284

\section{REFERENCES}

1. Roh E, Kim JE, Kwon JY, et al. Molecular mechanisms of green tea polyphenols with protective effects against skin photoaging. Crit Rev Food Sci Nutr. 2017;57(8):1631-1637.

2. Silveira JEPS, Pedroso DMM. UV light and skin aging. Rev Environ Health. 2014;29(3):243-254.

3. Stege PW, Davicino RC, Vega AE, Casali YA, Correa S, Micalizzi B. Antimicrobial activity of aqueous extracts of Larrea divaricata Cav (jarilla) against Helicobacter pylori. Phytomedicine. 2006;13:724-727.

4. Zampini IC, Cudmani N, Isla MI. Actividad antimicrobiana de plantas medicinales argentinas sobre bacterias antibiótico-resistentes. Acta Bioquímica Clínica Latinoamericana. 2007;41:385-393.

5. Moreno MA, Córdoba S, Zampini IC, et al. Argentinean Larrea Dry Extracts with Potential Use in Vaginal Candidiasis. Nat Prod Commun. 2018;13(2):171-174.

6. Davicino R, Manuele MG, Turner S, Ferraro G, Anesini C Antiproliferative activity of Larrea divaricata Cav. on lymphoma cell line: participation of hydrogen peroxide in its action. Cancer Invest. 2010;28:13-22.

7. Butassi E, Svetaz LA, Ivancovich JJ, Feresin GE, Tapia A, Zacchino SA. Synergistic mutual potentiation of antifungal activity of Zuccagnia punctata Cav. and Larrea nitida Cav. extracts in clinical isolates of Candida albicans and Candida glabrata. Phytomedicine. 2015;22:666-578.

8. Isla MI, Moreno A, Nuño G, Carabajal A, Alberto MR, Zampini IC Zuccagnia punctata Cav.: A review of its traditional uses, phytochemistry, pharmacology and toxicology. NPC-Review. Nat Prod Comm. 2016;11:1749-1755.

9. Moreno MA, Gomez-Mascaraque L, Arias M, et al. Electrosprayed Chitosan Microcapsules as Delivery Vehicles for Vaginal Phytoformulations. Carbohydr Polym. 2018;201:425-437.
10. Carabajal MPA, Perea MC, Isla MI, Zampini IC. The use of jarilla native plants in a Diaguita-Calchaquí indigenous community from northwestern Argentina: An ethnobotanical, phytochemical and biological approach. J. Ethnopharm. 2020;247:112258.

11. Gómez J, Simirgiotis MJ, Manrique S, et al. UHPLC-HESI-OT-MS-MS biomolecules profiling, antioxidant and antibacterial activity of the "orange-yellow resin" from Zuccagnia punctata Cav. Antioxidants. 2020;9(2):123.

12. Moreno MA, Zampini IC, Isla MI. Antifungal, anti-inflammatory and antioxidant activity of bi-herbal phytotherapic using medicinal plants from Argentina highlands. J. Ethnopharm. 2020;253:112642.

13. Roco J, Alarcón G, Medina M, Zampini IC, Isla MI, Jerez S. Oral administration of Zuccagnia punctata extract improves lipid profile, reduces oxidative stress and prevents vascular dysfunction in hypercholesterolemic rabbits. Phytomedicine. 2018;48:104-111.

14. EMA. Guideline on declaration of herbal substances and herbal preparations in herbal medicinal products/traditional herbal medicinal products. 2010. Available at http://www.ema.europa.eu/docs/ en_GB/document_library/Scientific_guideline/2009/09/WC500 003272.pdf. Accesed in December 2019.

15. Chompoo J, Upadhyay A, Fukuta M, Tawata S. Effect of Alpinia zerumbet components on antioxidant and skin diseases-related enzymes. BMC Complement Altern Med. 2012;12:106.

16. Bravo K, Duque L, Ferreres F, Moreno DA, Osorio E Passiflora tarminiana fruits reduce UVB-induced photoaging in human skin fibroblasts. J Photochem Photobiol. 2017;168:78-88.

17. Thitimuta $S$, Pithayanukul $P$, Nithitanakool $S$, Bavovada $R$, Leanpolchareanchai J, Saparpakorn P Camellia sinensis L. Extract and its potential beneficial effects in antioxidant, anti-inflammatory, anti-hepatotoxic, and anti-tyrosinase activities. Molecules. 2017;22(3):401.

18. Mahapatra DK, Bharti SK, Asati V. Chalcone derivatives: Antiinflammatory potential and molecular targets perspectives. Curr Top Med Chem. 2017;17(28):3146-3169.

19. Mandrone M, Lorenzi B, Venditti A, et al. Antioxidant and anti-collagenase activity of Hypericum hircinum L. Ind Crop Prod. 2015;76:402-408

20. Pientaweeratch S, Panapisal V, Tansirikongkol A. Antioxidant, anti-collagenase and anti-elastase activities of Phyllanthus emblica, Manilkara zapota and silymarin: An in vitro comparative study for anti-aging applications. Pharm Biol. 2016;54(9):1865-1872.

21. Gongx S, Xue Z, Liao S. The effect of NDGA-modified etchant on the enzymatic degradation resistance and mechanical properties of collagen matrix. Chin Chem Lett. 2018;29:205-208.

22. Moon H, Jung JC. Retracted: Effect of Meso-dihydroguaiaretic acid from Machilus thunbergii Sieb et Zucc on MMP-1 expression in heat shock-induced cultured primary human fibroblasts. Phytother Res. 2006;20(8):714-716.

23. Sacan O, Akev N, Yanardag R. In vitro inhibitory effect of Aloe vera (L.) Burm. f. leaf extracts on the activity of some enzymes and antioxidant activity. Indian J Biochem Biophys. 2017;54:82-89.

24. Wu Y, Sureshbabu M, Fang $Y$, et al. Potent inhibition of human neutrophil activations by bractelactone, a novel chalcone from Fissistigma bracteolatum. Toxicol Appl Pharm. 2013;266:399-407.

25. Feng L, Liu X, Zhu W, et al. Inhibition of human neutrophil elastase by pentacyclic triterpenes. PLoS One. 2013;8(12):e82794.

26. Saranraj P, Naidu MA. Hyaluronic acid production and its applications- a review. Int J Pharm Biol Arch. 2013;4:853-859.

27. Liyanaarachchti GD, Samarasekera JKRR, Mahanama KRR, Hemalal KDP. Tyrosinase, elastase, hyaluronidase, inhibitory and antioxidant activity of Sri Lankan medicinal plants for novel cosmeceuticals. Ind Crops Prod. 2018;111:597-605.

28. Petrey AC, de la Motte CA. Hyaluronan, a crucial regulator of inflammation. Front. Immunol. 2014;5:101. 
29. Blecha JE, Anderson M, Chow J, et al. Inhibition of IGF-1R and lipoxygenase by nordihydroguaiaretic acid (NDGA) analog. Bioorg Med Chem. 2007;17:4026-4029.

30. Khatib S, Nerya O, Musa R, Shmuel M, Tamir S, Vaya J. Chalcones as potent tyrosinase inhibitors: the importance of a 2, 4-substituted resorcinol moiety. Bioorg Med Chem. 2005;13(2):433-441.

31. Akhtar MN, Sakeh NM, Zareen S, et al. Design and synthesis of chalcone derivatives as potent tyrosinase inhibitors and their structural activity relationship. J Mol Struct. 2015;1085:97-103.

32. Fan M, Ding H, Zhang G, Hu X, Gong D. Relationships of dietary flavonoid structure with its tyrosinase inhibitory activity and affinity. LWT. 2019;107:25-34.
How to cite this article: Orqueda ME, Moreno MA, Zampini IC, Bravo K, Osorio E, Isla MI. Potential use of medicinal plants from Argentinean highland as agent anti-photoaging. J Cosmet Dermatol. 2020;00:1-9. https://doi.org/10.1111/ jocd.13701 